\title{
A Blockchain Infrastructure for Transportation in Low Income Country Cities, and Beyond
}

Simon J Herko

TravelSpirit Foundation, UK

Correspondence: siho@travelspirit.io

Received: 26 August 2019 Accepted: 29 August 2019 Published: 5 September 2019

\begin{abstract}
For our cities of tomorrow, it is essential that transport is organised in an efficient, resilient and equitable way; enabling economic growth, social cohesion and minimising environmental impacts, including Climate Change. In cities across the world, new flexible, sharing economy services are blurring the lines between private and public transportation. However, these new transport modes are creating a "digital divide" and lack the integration and co-ordination between other services. This is needed to create seamless and sustainable travel options for people, including those belonging to vulnerable groups. This exploratory paper examines the potential for Blockchain to play a pivotal role in addressing increasing congestion and pollution in growing cities of developing countries. It draws on preliminary research into the role of Automatic Fare Collection systems and related mobility market dynamics and trends in the cities of Cape Town, South Africa and Dehli, India. By creating viable new digital infrastructure for Low Income Country Cities (LICCs), who have less incumbent legacy systems, there is potential to establish a decentralised blockchain network across these territories. There would also be scope for this network to be scaled further into wealthier countries, through a secondary wave of adoption by Mobility-as-a-Service (MaaS).
\end{abstract}

Keywords: blockchain, transportation, mobility as a service, low income countries, cities, disruptive technology, infrastructure

JEL Classifications: A13, B41, C60, C71, D41, D43, D63, E24, E26, F02, F60, L14, L16, L17, L91, O18, O33

\section{The challenge of integrating mobility services}

The proportion of the world's population living in urban areas will approach $66 \%$ by $2050[1]$, with much of this growth coming from Low Income Country Cities (LICCs).

However, transport in LICCs is fragmented, with no common standards for booking, payment and service delivery across different modes of transport, competing services or across regions. The majority of data is yet to be digitised and there are no mechanisms in place to support data-sharing of movements and assets. This leads to inefficient transport provision, impacting economic and social well-being and increasing congestion and pollution levels, including unsustainable carbon emissions that are accelerating Climate Change.

\section{Developing the evidence base}

We identified the high growth and congested cities of Cape Town, South Africa and Delhi, India, as suitable real-world case studies for examining the potential for blockchain to provide common infrastructure for LICCs.
Our research into the Cape Town and South African context was undertaken in collaboration with the Greater Tygerberg Partnership (GTP). The GTP is a not-for-profit entity funded by the City of Cape Town, under the Transport and Urban Development Authority. It serves as a facilitator to economic and social renewal and collaborative efforts between the private sector, civil society, academic institutions and government for the benefit of the Voortrekker Road Corridor (VRC). The VRC is an identified integration zone and inward investment opportunity area, comprising a population circa 350,000. It acts as the second largest economic hub and busiest transport hub in the Western Cape.

By researching the economic and social conditions in Cape Town and the wider South African region, we have developed key insights into the challenge of bringing together transportation within and across LICCs.

In South Africa, the proportion of individuals benefiting from social grants rose from $12.7 \%$ in 2003 to $29.9 \%$ in 2016 [2]. The unemployment rate in South Africa is $26.7 \%$ [3]. Access to 
transport is a key enabler for accessing employment and education opportunities.

In the public and charitable sectors, transport funding subsidies are often applied to the infrastructure, not the user, creating a lack of transparency and often inefficient utilisation of scarce resources.

Although improving, a high proportion of the population (23\%) are unbanked [4] and 63\% are without access to smartphones [5]. Credit card penetration is at $17 \%$ and $65 \%$ of all transactions are made by cash. $54 \%$ of the population could be persuaded to switch from cash to digital wallets only if they provided a significant value-add over cash [6].

The following research insights are of particular relevance to the opportunity for a blockchain-based infrastructure intervention:

1. Competing transport businesses, including high levels of "informal" minibus taxi operations, make aggregation of services and data highly challenging and encourage disreputable operators. A commercially agnostic platform that is easy and compelling to adopt would therefore be highly desirable.

i. In South Africa, the proportion of the population who use informal minibus taxis rose from $17.6 \%$ in 2003 to $22.4 \%$ in 2013. The proportion of mass-transit commutes that are carried by minibuses is $67.5 \%$ [7].

ii. Customer dissatisfaction with minibuses is very high $26.5 \%$, compared to $3.9 \%$ for trains and $4.2 \%$ for buses.

2. In mass transit, the gap between fare revenues collected and passenger numbers serviced is too high, inhibiting further investments in infrastructure and a negative impact on the affordability of fares. Transit providers require higher surety of payment.

i. Affordability of mass transit has an impact on poverty, inclusivity and the economy [8].

ii. Cape Town buses have introduced a Smart Card and are enjoying growth [9].

iii. Western Cape rail revenues are in decline due to unreliable services and poor funding [10].

For comparison with the South African research, we reviewed the transport landscape and relevant scientific papers for the National Capital Territory (NCT) of Delhi, India and its wider National Capital Region, including the significance of the Metro for rapid transit and active travel (i.e. non-motorised transport) for first and last mile access.

Despite rapid growth of the Metro network, the lack of integration of different modes has hastened the shift towards private automobiles, including two-wheelers and increasingly four-wheelers, for commuting and other short distance travel. Over the course of 2015-2016 alone, the number of private motor vehicles registered within the NCT of Dehli rose 10 percent, from 8.8 million to 9.7 million, and the trend is expected to continue without dramatic shifts in planning policy [11].

Price and first/last mile connectivity are the major influencing factors on choice of transport mode, demonstrated in shifts from Metro (faster with poorer last mile access, thus supplemented by auto hire) to bus (slower with better last mile access) amongst middle and lower income commuters following a Metro fare hike over the 2016-2017 fiscal year [12] [13].

The following insights should help inform the design and rollout of blockchain-based infrastructure for enhancing the ease of multi-modal trips, including the need to consider how funding for infrastructure to support active travel can be integrated into the conceptual framework:

1. Poor first and last mile connectivity of public transit, especially the Metro, is hampering the effectiveness of public transit at reducing congestion and enhancing mobility. Furthermore, transfers between metro and bus for first/last mile trip segments require separate fare payment methods, given the Metro fare payment card is not widely accepted by bus operators, despite pledges by operators to install card readers [14].

i. Offering convenience expected of private motoring, especially door-to-door service, can help reverse the decline in modal share of public transit [15].

ii. Physical facilities for active travel tend to be substandard or absent, leading to greater reliance on private cars, reduced street space for walkers and cyclists, and declining ridership of bus transit [16].

iii. Funding for completion of discontinuous footpaths, regular maintenance, and prevention of encroachments are expected to boost the propensity of active travel [17].

2. Mobility providers including bus operators, ride-hailing and cycle-share platforms do not coordinate with each other, leaving certain areas of the city grossly underserved relative 
to potential trip demand and, in the case of separate companies operating buses and metro trains, leading to lower than expected ridership on new metro lines. Local authorities are evidently aware of this shortcoming, as demonstrated by the launch of One Delhi mobile application for real time journey planning covering both bus and metro lines [18].

i. The benefits of a common mobility account have merited endorsement by the highest levels of the central government, including the Vice President in a call to combat vehicular pollution through improved ease of using public transport [19].

ii. There is a desire to address the lack of coordination by bringing ideally all mobility providers under a common organisational umbrella [20]. This desire, in practice may not be achievable, pointing towards a role of a blockchain infrastructure to support a multi-stakeholder eco-system with no centralised control.

iii. A study for a cycle sharing system that is ready for fares integration with other transport modes is ongoing in South Delhi [21].

\section{Our working hypotheses on a viable blockchain}

Our research is motivated by a hypothesis that, less hampered by legacy infrastructure and with strong economic drivers for innovation, LICCs can leapfrog high income countries on Intelligent Transport Systems (ITS) [22]. This would imply:

1. LICCs do not have to depend upon large programme budgets (which aside from the expense can be often open to corruption) and enter complex procurements to drive forward and realise technology-driven benefits.

2. There are ways for emerging economies to innovate faster than developed markets and play the role of pilot/pioneers in blockchain.

More specifically, there is an opportunity for a common blockchain network infrastructure, for transport booking, payments and subsidies, that, starting with Low Income Country Cities (LICCs), would enable all cities to enjoy the benefits of an integrated transport system that is interoperable across competing services and inter-regional borders.

As highlighted in our South African evidence base (while applicable across much of the African, Indian, Asian and South American continents) the informal minibus taxi sector is a complex environment, while a key ingredient to the transport mix of many LICCs. It is ripe for change, especially with regards to new payment models and methods to optimise and integrate systems.

Following an examination of the current Intelligent Transport Systems (ITS) landscape in LICCs, we identified the most compelling blockchain use-case to be for Automatic Fare Collection (AFC). A common global and universal "open-loop" infrastructure, enabled by blockchain, would replace the need for bespoke and centralised back-office systems for each city, and provide a common payment system for the informal minibus taxi sector.

Both the European Bank for Reconstruction and Development (EBRD) and World Bank have identified the key barriers to adoption of "open-loop" account-based systems outside the largest and most affluent of world cities, such as Washington D.C. Boston, London, Amsterdam, Vienna, Singapore, Hong Kong and Seoul [23] [24]. They are the cost, time and effort required to obtain the necessary banking security permissions and the complexities of public sector led procurement and implementation, which can take up to 5 years to complete.

Advanced contactless card systems in London, Hong Kong and Singapore are made possible by an effective monopoly over transport provision and a well-funded co-ordinating body (e.g. TfL's operational budget is over $f^{6} 6$ billion per annum). They generally do not extend to new collective transport innovations such as car clubs, ride-hailing and bike-sharing; especially if operated privately. In this respect, they are less helpful operating models to replicate in emerging market economies, with their higher levels of market fragmentation, and where informal private minibus services often dominate mass transit.

Research undertaken for the World Economic Forum [25] articulates the case for improved integration and interoperability in city transportation and its potential for positive impact on global prosperity, equality and the environment. Their hypothesis is that a centralised global platform is required, risking, in our view, bringing transport under the control of a small set of data monopolies.

Our working hypothesis is that a permission-based blockchain solution could provide users equitable and open market access to transport services, with cashless, subscription-based and/or subsidised payment mechanisms. The solution would supersede "closed-loop" AFC technology (e.g. smartcards) on buses and trains and provide viable infrastructure to the informal minibus 
taxi market, which represents circa $70 \%$ of all mass transit trips in LICCs.

The rationale for adoption could be as follows, in terms of benefits for different stakeholders.

\section{Benefits to End Users:}

1. Cashless and trusted solution, improving safety $\&$ security.

2. Access to user-based subsidies and micro-credit worthiness.

3. Access without smartphone or contactless banking.

4. Develop personal identity and data profile.

5. Roaming capability.

Benefits to Transport Providers:

1. Surety of payment and uplift in fare revenues collected.

2. Access to customer data and new markets.

3. Fair and trustworthy subsidy compensation mechanisms.

Benefits to Cities:

1. Shift to mass-transit and reduced congestion/pollution.

2. Platform for inward investment into public transport infrastructure.

3. Easier to allocate subsidies in line with policy objectives (e.g. active travel).

4. Affordable, easy to adopt AFC solution.

These benefits would be delivered through decentralised, selfsovereign and interoperable "mobility accounts", hosted on a permission-based blockchain [26]. This includes smart contracts to execute commercial agreements, a shared set of business rules for innovation in fares policy and blended financial subsidies, including user-based subsidy.

The primary goal of the blockchain would be to provide all LICCs with a common global ITS (Intelligent Transport Systems) infrastructure, whose adoption could be achieved organically, rather than procured. We anticipate an open, transparent and crowd-based governance structure and token economy that will ensure transaction costs remain affordable.

\section{Technical characteristics of a suitable blockchain}

In researching the feasibility of a blockchain solution in the South African context, we identified the following initial functional requirements to establish a viable blockchain solution and adopted network:

1. Users (including the unbanked) to access multiple transport services through a global mobility account.

2. Account system interoperability and roaming capability between transport operators, modes and across regional borders.

3. Manage rights and responsibilities of portable personal data.

4. Support trusted multi-lateral commercial arrangements between transport providers.

5. Provide low network latency, fast verification and compatibility with low power devices.

6. Resilience to fraud and denial-of-service attacks.

7. Commercially agnostic solution that can be easily adopted by competing transport providers and multiple regions and cities.

8. Close integration with existing infrastructure, and a distributed share of transaction revenues.

The decentralised delivery model of an open-source and permission-based blockchain network would also seek to address the high expense and long duration of ITS procurements for AFC implementation.

Through dialogue with Hyperledger Working Requirements Group, we have identified the Hyperledger Indy and Hyperledger Sawtooth development frameworks and modular open-source codebase as the starting point [27] [28] [29]. To meet the above functional requirements, we anticipate the following future research and development actions:

\subsection{Proof of Location within the Trusted Execution Environment (TEE)}

Existing Sawtooth framework accesses an efficient Proof of Elapsed Time lottery algorithm for network consensus, via a TEE developed by Intel. There is opportunity to explore a new TEE that is optimised for deployment in low power devices, including a Proof of Location to improve network security and mobility account operation.

\subsection{Sharding / partitioning of the global state}

Existing Sawtooth framework requires consensus of the entire global state of transactions, with a total ordering of every transaction. There is an opportunity for our blockchain network 
to be partitioned or 'sharded' by location, to improve scalability and reduce storage requirements. A new framework could be developed to spawn multiple permissioned overlays of Sawtooth, enabling a segmented-state management protocol.

\subsection{On-Chain Smart Contracts with "Seth"}

There is scope to research into the capabilities of the new Seth transaction family [30] as a means for deploying Turing complete programs for compensation, arbitration and concessionary re-imbursement processes.

\subsection{Linking via "Seth", to a token-based economic model}

Hyperledger frameworks are optimised for the application of permissioned blockchains within business enterprise solutions using a centralised platform business model. A design goal of commercially agnostic, distributed revenues requires a higher level of decentralisation.

There is scope for using Seth to bridge between the Sawtooth permissioned framework and Ethereum-based tokens, to enable each city and transport provider to operate their own node and gain a share in the transaction revenues.

\section{Beyond LICCs: global Mobility as a Service (MaaS)}

Mobility as a Service (MaaS) is a new disruptive business model paradigm [31]. With an expected market size of $\$ 1$ trillion by 2030 , it will empower users with hassle-free payment options and an integrated approach to accessing public transport, flights, ferries and shared economy services.

To scale globally, MaaS requires commercial collaboration between a diverse and large transport ecosystem [32], and affordable solutions for Low Income Countries. Latest public policy and industry thinking would suggest a growing consensus that such collaboration would require a greater level of "openness", both culturally and technically, within the city transport sector, than currently exists in most city states [33].

Furthermore, to satisfy the demands of inter-regional and international travel, supporting MaaS platforms need crossborder functionality, facilitating "roaming" across cities and countries. They must also integrate various public, charitable, private and consumer funding sources to enable effective investment in mass transit and active travel infrastructure.
In a small collection of cities within wealthier countries, that also enjoy advanced Open Data programmes (e.g. Finland, Germany and the Netherlands), some MaaS apps are already covering a full spectrum of collective transport services. They have, in our view, limited scope for widespread adoption due to the centralised platform approach - i.e. the "unwanted thirdparty aggregator". This is a problem blockchain could solve by enabling personalised aggregation to take place direct to consumer, via a trusted, commercially agnostic and decentralised infrastructure.

While there are many new blockchain solutions appearing for shipping and logistics, the application of blockchain for MaaS is in its infancy. We have identified just over half a dozen published research papers on blockchain for MaaS, from Germany, Sweden, UK (by the Transport Systems Catapult and TravelSpirit Foundation), Finland and the Netherlands [26][34][35][36][37][38][39]. This growing evidence base corroborates with our thesis that the scope of MaaS to scale effectively, even within the European market, where public policy and industry interest is the greatest, is limited without the support of a common blockchain infrastructure.

With a focus on wealthier markets, the papers we have reviewed on the application of blockchain for MaaS do not make direct references to LICC contexts. We therefore believe we have developed a novel concept for how to scale a blockchain network for ultimate adoption as a MaaS solution in wealthier countries.

\section{Conclusion}

The potential global impact of a blockchain-based network infrastructure on the city transportation sector is substantial. With blockchain, we can ensure a healthier democratisation of the transport economy, that, based upon liberal philosophies, will provide autonomy to local and regional economies, strengthening global collaboration and regional governance.

A case has been made for a global and universal blockchain infrastructure, for the sharing of data on movement and assets, designed with low income economies and vulnerable groups in mind. It would enable:

1. Users' access to different modes of transport in an equitable and hassle-free way.

2. Assurance to transport operators on surety of payment. 
3. Cities with integrated solutions for tackling congestion and targeting subsidies.

Through the work of both the European Bank for Reconstruction \& Development and the World Bank, the economic and social case for delivering Automated Fare Collection (AFC) technology in transportation systems in emerging markets is already supported by a comprehensive evidence base. Existing research on AFC solutions consistently focuses on centralised platforms and bespoke back-office infrastructure for each city. It means the opportunity for a global infrastructure, delivered through a decentralised and networked route to market, has not been researched and advocated to the same extent.

In wealthier countries Mobility-as-a-Service (MaaS) is a new business model that integrates public and private services together. Its level of adoption could be limited without a supporting blockchain infrastructure. By creating viable new digital infrastructure for Low Income Country Cities (LICCs), who have less incumbent legacy systems, there is potential to establish a decentralised blockchain network across these territories. There would also be scope for this network to be scaled further into wealthier countries, through a secondary wave of adoption by Mobility-as-a-Service (MaaS).

To advance our understanding of this alternative vision for global AFC infrastructure (i.e. technology that is universal and enables a decentralised approach to the management and orchestration of transport) we'd recommend there to be:

1. Technology-based research and development on the Hyperledger Project open-source codebases.

2. Interventional pilots in Low Income Country Cities, and research into the institutional, commercial and funding mechanisms that would be required to establish and scale this kind of universal blockchain infrastructure.

\section{Competing Interests:}

None declared.

\section{Ethical approval:}

Not applicable.

\section{Author's contribution:}

SIH designed and coordinated this research and prepared the manuscript in entirety. Funding:

None declared.

\section{Acknowledgements:}

SJH would like to thank his colleagues at the TravelSpirit Foundation and Iconic Blockechain for their support and encouragement over the past 2 years, in particular to David Alexander, Giles $K$ Bailey, Justin Coetzee, Mike Fitzgerald, Dr Pieter I Fourie, Bren Hutchinson, Dr Maria Kamargianni, Nathan King, Rob Mann, Gary Parkinson and Yangbo Du. Also, special thanks to Johan Muller and Warren Hewitt at the Greater Tygerberg Partnership and Mark Rathbone at Brabners LLP.

\section{References:}

[1] “World Urbanization Prospects - Population Division,” United Nations. [Online]. Available: https://population.un.org/wup/. [Accessed: 16-Aug-2018].

[2] "General Household Survey, 2016," Department Statistics South Africa. [Online]. Available: http://www.statssa.gov.za/?p=9922

[3] "Quarterly Labour Force Survey - QLFS Q4:2017” Department Statistics South Africa. [Online]. Available: http:/ / www.statssa.gov.za/?p=10884

[4] "Credit Card vs Cash in Africa - on the verge of convergence" Cape Business News (2019). [Online] Available: https://www.cbn.co.za/opinion/credit-card-vs-cash-in-africa-onthe-verge-of-convergence/

[5] "In South Africa, Cash Is Still Right On The Money" PYMNTS.com (2019). [Online] Available: https://www.pymnts.com/cash/2017/south-africa-cash-usage/

[6] "Mobile wallets 'key' to SA e-commerce," Fin24tech, 30-Mar-2016. [Online]. Available: https://www.fin24.com/Tech/Mobile/mobilewallets-key-to-sa-e-commerce-20160330

[7] P. Lehohla, "Transport Series Volume I: Profile of non-motorised transport users: In-depth analysis of the National Household Travel Survey 2013 data," Department Statistics South Africa, rep. Available: http://www.statssa.gov.za/publications/Report-71-0301/Report-71-03-012013.pdf

[8] R. Carruthers, M. Dick, and A. Saurkar, "Affordability of Public Transport in Developing Countries," The World Bank Group, rep., Jan. 2005. Available: http:/ / siteresources.worldbank.org/INTTRANSPORT/2145781099319223335/20460038/TP-3_affordability_final.pdf

[9] "Golden Arrow hits profit targets." Cape Business News. (2019). [Online] Available: https://www.cbn.co.za/news/golden-arrowhits-profit-targets/

[10] C. Presence, "Metrorail losing paying customers by the millions, MPs told,” IOL News, 17-Apr-2018. [Online]. Available: https://www.iol.co.za/news/south-africa/western-cape/metroraillosing-paying-customers-by-the-millions-mps-told-14494831

[11] S. Pillai, "Poor public transport behind Delhi vehicle boom, say experts," Hindustan Times, 20 Dec. 2016. Available: https://www.hindustantimes.com/delhi/poor-public-transportbehind-delhi-vehicle-boom-say-experts/story4lbiZTogbYPofE2A57zcCJ.html

[12] A. Roychowdhury, "Towards Clean and Low Carbon Mobility: Addressing Affordability and Scaling up of Sustainable Transport," Centre for Science and Environment, rep., Sep. 2018. Available: http://cdn.cseindia.org/attachments/0.21487000_1536054529_An umita-Clean-low-carbon-mobility-strategy-Sept.pdf

[13] C. Kumar and A. Ganguly, "Travelling Together but Differently: Comparing Variations in Public Transit User Mode Choice Attributes Across New Delhi and New York," Theoretical and Empirical Researches in Urban Management, vol. 13, no. 3, pp. 5473, Aug. 2018. Available: https://www.jstor.org/stable/pdf/26472536.pdf?refreqid=excelsio r\%3Aba21b9e6215c4ee0989116576282054a

[14] "Use metro cards on buses for discount," The Hindu, 20 Oct. 2018. Available: https://www.thehindu.com/news/cities/Delhi/usemetro-card-on-buses-for-discount/article25266914.ece

[15] O. P. Agarwal, "Compulsion to Choice: How Can Public Transport in India Be Transformed," Economic and Political Weekly, vol. 54, no. 4, 26 Jan. 2019. Available: https://www.epw.in/node/153650/pdf. 
[16] "U. Nasim and V. Chattopadhyay, "Indian roads belong to motorised vehicles, not cyclists or pedestrians," Down to Earch, 6 Nov. 2018. Available:

https://www.downtoearth.org.in/news/air/indian-roads-belong-tomotorised-vehicles-not-cyclists-or-pedestrians-62049

[17] M. A. Alam, "Sustainable and Equitable Transport System in Delhi: Issues and Policy Direction," Asian Institute of Transport Development, rep., 2015, Available:

https://www.unescap.org/sites/default/files/Article\%202_Sustaina ble $\% 20$ and $\% 20$ equitable $\% 20$ transport $\% 20$ system $\% 20$ in $\% 20$ Delhi.p df

[18] "Delhi commuters can now locate public transport better with 'One Delhi' app," Press Trust of India, First Post, 6 Mar. 2019. Available: https://www.firstpost.com/tech/news-analysis/delhi-commuterscan-now-locate-public-transport-better-with-one-delhi-app6205941.html

[19] "VP calls for a public transport-centric approach to combat growing vehicular pollution," Government of India Press Information Bureau, 3 May 2019. Available:

https://pib.gov.in/newsite/PrintRelease.aspx? relid=189925

[20] "Reimagining public transport in India," KPMG, rep., Oct. 2017. Available:

https://assets.kpmg/content/dam/kpmg/in/pdf/2017/10/Reimag ining-public-transport.pdf

[21] "Draft Detail Project Report on Public Bicycle Sharing System for SDMC (South Delhi Municipal Corporation)," Centre for Green Mobility, rep., Sep. 2015. Available:

https://shaktifoundation.in/wp-content/uploads/2017/06/PublicBicycle-Sharing-DPR-South-Delhi.pdf

[22] T. Yokota, "ITS Technical Note for Developing Countries," World Bank Group, rep., Jul. 2004. Available: http://siteresources.worldbank.org/EXTROADSHIGHWAYS/Re sources/ITSNote1.pdf

[23] "On the move: delivering automated fare collection," European Bank for Reconstruction and Development, rep., Jul. 2017. Available: https://www.ebrd.com/documents/admin/on-themove-delivering-automated-fare-collection.pdf

[24] C. Monsalve et al, "Public Transport Automatic Fare Collection Interoperability: Assessing Options for Poland” World Bank Group and Korea Green Growth Partnership, rep., Jun. 2016. Available: http://documents.worldbank.org/curated/en/56400146900991644 1/pdf/107014-WP-P148489-PUBLIC-Phase-2-Public-TransportAFC-Interoperability-Final-Report-June-10-2016.pdf

[25] J. Moavenzadeh and V. Padilla-Taylor, "Designing a Seamless Integrated Mobility System (SIMSystem)," World Economic Forum, rep., Jan. 2018. Available: http://www3.weforum.org/docs/Designing_SIMSystem_Manifest o_Transforming_Passenger_Goods_Mobility.pdf

[26] S. Ho et al, "TSio Protocol: The Internet of Mobility," Whitepaper, TravelSpirit Foundation, UK, rep., Dec. 2017. Available: https://travelspirit.foundation/wpcontent/uploads/2017/12/TravelSpirit-WhitePaper-TSio-Protocol$\mathrm{v}-6-1 . \mathrm{pdf}$

[27] "Hyperledger Architecture Volume 1, Design Philosophy and Consensus" Linux Foundation, rep., Aug. 2017. Available: https://www.hyperledger.org/wpcontent/uploads/2017/08/Hyperledger_Arch_WG_Paper_1_Cons ensus.pdf

[28] "Hyperledger Architecture Volume II, Smart Contracts" Linux Foundation, rep., Apr. 2018. Available:

https://www.hyperledger.org/wpcontent/uploads/2018/04/Hyperledger_Arch_WG_Paper_2_Smar tContracts.pdf

[29] K. Olson, M. Bowman, J. Mitchell, S. Amundson, D. Middleton, and C. Montgomery, "Hyperledger Sawtooth: An Introduction," Linux Foundation, rep., Jan. 2018. Available: https://www.hyperledger.org/wpcontent/uploads/2018/01/Hyperledger_Sawtooth_WhitePaper.pdf
[30] "Seth Transaction Family Specification" Hyperledger Project [Online, accessed Jun. 2019]. Available: https://sawtooth.hyperledger.org/docs/core/releases/0.8/transacti on_family_specifications/sawtooth_burrow_evm_family.htm

[31] M. Kamargianni and M. Matyas, "A Holistic Overview of the Mobility-as-a-Service Ecosystem" University College London, rep. Mar. 2017, Available: https://docs.wixstatic.com/ugd/a2135d_8ec5294674a44129b04bcc 99a324d1c5.pdf

[32] P. Karjalainen, "Guidelines \& Recommendations to create the foundations for a thriving MaaS EcoSystem", MaaS Alliance, rep. Sep. 2017, Available: https://maas-alliance.eu/wpcontent/uploads/sites/7/2017/09/MaaSWhitePaper_final_040917-2.pdf

[33] S. Herko, S. Witzel, P. Karjalainen et al, “An Open Future for Cities: Preparing cities for the necessary transformation and organisational changes needed for an open future." Whitepaper, TravelSpirit Foundation, UK, rep., Dec. 2017. Available: https://www.researchgate.net/publication/334524614_An_Open_ Future_for_Cities_Preparing_cities_for_the_necessary_transformati on_and_organisational_changes_needed_for_an_open_future

[34] D. Sümmermann, C. D. Öge, M. Smolenski, G. Fridgen, and A. Rieger, "Open Mobility System", Concept Paper, MotionWerk GmbH, Fraunhofer FIT, TUV Rheinland, Germany, rep., Sep. 2017 Available: https://www.omos.io/wpcontent/uploads/whitepaper/OMOS_concept_paper.pdf

[35] P. Andersson and J. Torstensson, "Exploring the role of blockchain technology in Mobility as a Service,", Master's Thesis, Chalmers University of Technology, Gothenberg, Sweden, rep., Nov. 2017. http://publications.lib.chalmers.se/records/fulltext/252507/25250 7.pdf

[36] "Blockchain Disruption in Transport: Are You Decentralised Yet?" Transport Systems Catapult, UK, rep., Jun. 2018. Avaliable: https://s3-eu-west-1.amazonaws.com/media.ts.catapult/wpcontent/uploads/2018/06/06105742/Blockchain-Disruption-inTransport-Concept-Paper.pdf

[37] A. Karinsalo and K. Halunen, "Smart Contracts for a Mobility-as-aService Ecosystem,", Conference Paper, VTT Technical Research Centre of Finland, rep. Jul. 2018. Available: https://ieeexplore.ieee.org/abstract/document/8431964

[38] J. Verheul, M. Mijnheer, and J. Ferwerda, "A new Blockchain Platform Designed for the Future of Human Mobility,", Whitepaper, VMC, The Netherlands, rep., Jan. 2019. Available: https://vmc.ai/wp-content/uploads/2019/01/whitepaper.pdf

[39] T. Nguyen, J. Partula, S. Pirttikangas, "Blockchain-based Mobilityas-a-Service,", University of Oulu, Finland, Conference Paper, rep., May 2019. Available: https://www.researchgate.net/profile/Tri_Nguyen43/publication/ 333343145_Blockchain-based_Mobility-as-aService/links/5ce7e298a6fdccc9ddcabb45/Blockchain-basedMobility-as-a-Service.pdf 